\title{
A mechanistic review of plumbagin effects againts diabetes and obesity
}

\author{
Nurfitri Bustamam¹, Adelina Simamora ${ }^{2,3^{*}}$ \\ 1 Department of Physiology, Faculty of Medicine, Universitas Pembangunan Nasional Veteran Jakarta, Jakarta, Indonesia \\ 2 Department of Biochemistry, Faculty of Medicine and Health Sciences, Krida Wacana Christian University, Jakarta, Indonesia \\ 3 Centre for Enzyme Research in Health and Diseases, Krida Wacana Christian University, Jakarta, Indonesia
}

\begin{abstract}
Plumbagin, a plant-derived metabolite, is a naphthoquinone derivative which has been studied for its diverse pharmacological effects including antidiabetic and anti-obesity effects. The present review focusses on reports concerning the effects of plumbagin on diabetes and obesity, and its mechanisms underlying these effects. Plumbagin exerts its antidiabetic effect by modulating key enzymes in glycolysis including $\alpha$-glucosidase, hexokinase, and aldose reductase, and in gluconeogenesis such as glucose-6-phosphatase and fructose-1,6biphosphatase. In addition, plumbagin stimulates glucose uptake in skeletal muscle cells by increasing GLUT4 translocation. Plumbagin regulates lipid metabolisms, by inhibiting pancreatic lipase, a lipolytic enzyme. Further, its effect on lipolysis is indicated by an increase in hepatic peroxisome proliferator-activated receptor alpha (PPAR $\alpha$ ). Regulation of lipogenesis is observed with decrease in sterol regulatory element binding (SREB) in the liver. More mechanistic studies are in need to provide support for the development of plumbagin as a pharmacological-therapeutics for diabetes and obesity.
\end{abstract}

Keywords:

Antidiabetic, Anti-obesity, Antioxidant, Enzymes, Glycolysis, Lipid-lowering, Plumbagin

\section{INTRODUCTION}

Diabetes mellitus and obesity remains highly prevalent among different age groups worldwide ${ }^{1,2}$. Diabetes mellitus is one of the most common metabolic diseases which is characterized by impairment of glucose metabolism. This condition may be caused by defects in insulin secretion and/or cellular insulin resistance in the adipose tissue, the liver, and the skeletal muscles. Obesity is the main risk factor for the development of type 2 diabetes mellitus (T2DM). Obesity is associated with systemic inflammation leading to insulin resistance ${ }^{3}$. Diabetes and obesity are considered significant risk factors in the development of cardio vascular disease ${ }^{4}$, which is the first leading cause of mortality worldwide ${ }^{5}$. Report from International Diabetes Federation showed that 463 million people suffered from diabetes in 2019 . This number is projected to increase to 578 million by $2030^{6}$. Globally, the prevalence of obesity among adults
(>18 years old) in 2014 were $11 \%$ of men and $15 \%$ of women of the world population ${ }^{7}$. Diabetes has become financial burden for individuals, their families, and ultimately national economies. Health spending on diabetes reached USD 760 billion in 2019 worldwide and is estimated to grow to USD 845 billion by $2045^{\circ}$. Obesity imposes global economic burden, reaching USD 2.0 trillion in 2014 or $2.8 \%$ of global gross domestic products (GDP) ${ }^{9}$. These data represent significant health challenge of diabetes and obesity.

Plants remain the primary source for the discovery and development of antidiabetic and antiobesity agents ${ }^{10,11}$. Studies related to pure compounds of plant origin have shown promising responses against diabetes and obesity ${ }^{12-14}$. Plumbagin is one of naphthoquinone derivatives of which are arguably the largest plant secondary metabolites. Pharmacological studies have indicated that plumbagin and plant extracts containing plumbagin have anticancer ${ }^{15,16}$, anti-inflammatory ${ }^{17,18}$,

\section{*Corresponding author:}

*Adelina Simamora adelina.simamora@ukrida.ac.id 
antioxidant ${ }^{19,20}$, and antimicrobial ${ }^{21,22}$ activities. Literature reported that plumbagin and plant extracts containing plumbagin have shown promising therapeutic effects on diabetes and obesity. This review focusses on reports concerning the effects of plumbagin on diabetes and obesity, based on in vitro and in vivo studies. In addition, this review discusses the mechanisms underlying these effects.

\section{METHODS}

Relevant literature in English was retrieved up to February 2021 using electronic databases and search engine, including ScienceDirect, Scopus, and Google Scholar. Keywords used were (Plumbagin or Plumbago) and ("antidiabetic" or "hyperglycemia" or "diabetic" or "diabetes" "hyperlipidemia" or "obesity"). From ScienceDirect and Scopus, 98 and 40 articles were collected respectively, whereas from Google Scholar, 100 articles were collected. Only original articles were taken in the study. Irrelevant and duplication titles were excluded. Nine articles met the criteria and were included in the study.

\section{PHYSICOCHEMICAL PROPERTIES OF PLUM- BAGIN}

Plumbagin $\left(\mathrm{C}_{11} \mathrm{H}_{8} \mathrm{O}_{3}\right.$, Mw $\left.188.17 \mathrm{~g} / \mathrm{mol}\right)$ is a naphthoquinone derivative, with the IUPAC nomenclature 2-methyl-5-hydroxy-1,4-naphthoquinone. Plum- bagin is synthesized via acetate and malonovate pathway ${ }^{23}$. Plumbagin presents in plant families Plumbaginaceae, Ebenaceae, and Droseraceae. It is isolated mainly from the root, stem bark, and leaves as orange needle shaped crystal. In fact, the name plumbagin comes from the genus Plumbago from which it was firstly isolated ${ }^{24}$.

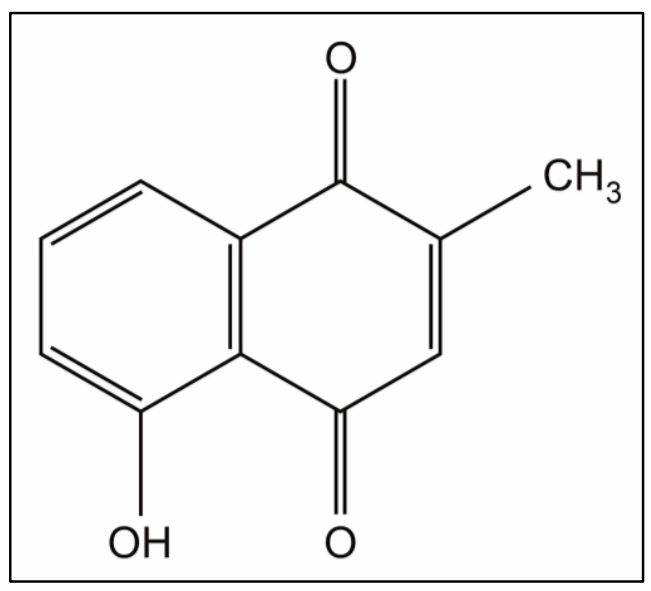

Figure 1. Plumbagin.

Study using animal model indicates that the oral bioavailability of plumbagin is $38.7 \%$ in a conscious freely moving rat receiving $100 \mathrm{mg} / \mathrm{kg}$ body weight of plumbagin ${ }^{25}$. The relatively low bioavailability could be due to its lipophilic nature, low solubility in water, and short biological half-life ${ }^{26}$.

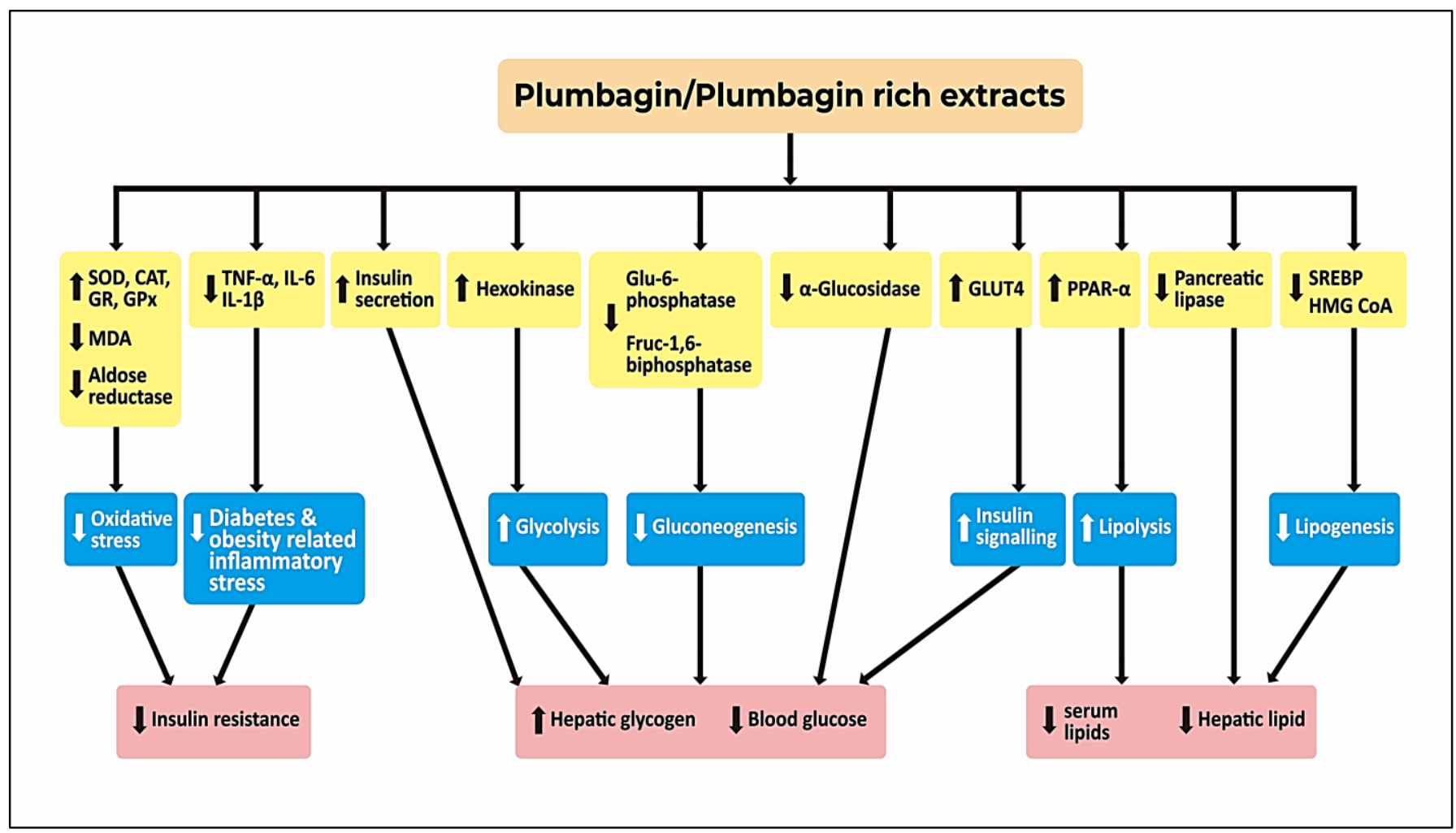

Figure 2. Effects and metabolic targets of plumbagin for the treatment of diabetes and obesity. 
Table 1. Plumbagin mechanisms as antidiabetic and anti-obesity agents.

\begin{tabular}{|c|c|c|c|}
\hline \multicolumn{2}{|c|}{ Effects } & \multirow[t]{2}{*}{ Organs/models } & \multirow[t]{2}{*}{ Ref } \\
\hline Upregulation/Stimulation & Downregulation/Inhibition & & \\
\hline $\begin{array}{l}\text { insulin levels } \\
\text { HDL, SOD, catalase, GPx, GR, GST }\end{array}$ & $\begin{array}{l}\text { blood glucose } \\
\text { TC, TG, LDL } \\
\text { TNF- } \alpha, \text { IL-6, IL-1ß levels }\end{array}$ & $\begin{array}{l}\text { skin, STZ-induced diabetic Wistar } \\
\text { albino rats }\end{array}$ & $(47)$ \\
\hline $\begin{array}{l}\text { PPAR- } \alpha \text { mRNA } \\
\text { serum HDL } \\
\text { GSH, SOD, catalase }\end{array}$ & $\begin{array}{l}\text { SREBP-1c mRNA } \\
\text { serum fasting glucose, insulin levels, HOMA- } \\
\text { IR } \\
\text { serum TG, TC, LDL, VLDL, hepatic TG, } \\
\text { cholesterol, FFA } \\
\text { lipid peroxidation in the liver } \\
\text { hepatic TNF- } \alpha, \text { IL-6, IL-1ß }\end{array}$ & $\begin{array}{l}\text { liver, fructose induced obesity \& } \\
\text { NAFLD in Wistar rats }\end{array}$ & $(42)$ \\
\hline $\begin{array}{l}\text { insulin levels } \\
\text { glycogen synthase } \\
\text { hexokinase } \\
\text { GLUT4 in skeletal muscle } \\
\end{array}$ & $\begin{array}{l}\text { blood glucose } \\
\text { glycogen phosphorylase } \\
\text { glucose-6-phosphatase, fructose-1,6- } \\
\text { bisphosphatase }\end{array}$ & $\begin{array}{l}\text { skeletal muscle, STZ-induced } \\
\text { diabetic Wistar albino rats }\end{array}$ & (29) \\
\hline GPx, GSH & liver HMGB1, NF- $\kappa B$, TNF- $\alpha$ & liver, Wistar albino rats & (29) \\
\hline hexokinase & glucose-6-phosphatase & $\begin{array}{l}\text { STZ-induced diabetic Wistar albino } \\
\text { rats }\end{array}$ & (53) \\
\hline & $\begin{array}{l}\text { pancreatic lipase (in vitro) } \\
\text { lipid absorption (in vivo) after oral fat } \\
\text { tolerance test } \\
\text { adipocyte differentiation } \\
\text { TG accumulation in adipocytes }\end{array}$ & $\begin{array}{l}\text { 3T3-L1 fibroblast cell line, } \\
\text { adipocytes, Wistar rats }\end{array}$ & (46) \\
\hline SOD1 expression in vitro & NADPH oxidase 4 (Nox4) expression in vitro & $\begin{array}{l}\text { human kidney- } 2 \text { cells, STZ induced } \\
\text { diabetic C57BL/6J mice }\end{array}$ & (49) \\
\hline SOD activity in vivo & & & \\
\hline $\begin{array}{l}\text { HDL/total cholesterol ratio } \\
\text { excrete fecal cholesterol \& } \\
\text { phospholipids }\end{array}$ & $\begin{array}{l}\text { serum cholesterol, LDL, VLDL } \\
\text { cholesterol/phospholipid ratio } \\
\text { TC, TG, phospholipid contents of liver and } \\
\text { aorta }\end{array}$ & $\begin{array}{l}\text { liver, aorta, cholesterol feeding } \\
\text { induced hyperlipidemic \& } \\
\text { atherosclerotic in rabbits }\end{array}$ & $(41)$ \\
\hline fecal cholesterol excretion & $\begin{array}{l}\text { serum TG, cholesterol levels } \\
\text { HMGCoA reductase activity or } \\
\text { cholesterolgenesis in liver }\end{array}$ & $\begin{array}{l}\text { hyperlipidemic induced in Wistar } \\
\text { rats by feeding a high fat diet }\end{array}$ & $(40)$ \\
\hline $\begin{array}{l}\text { potential free radical } \\
\text { scavenging effect }\end{array}$ & $\begin{array}{l}\text { liver content of total lipid } \\
\text { lipid peroxidation }\end{array}$ & & \\
\hline
\end{tabular}

Abbreviations: AGE: advanced glycation end-product, AR: aldose reductase, CD68: cluster of differentiation 68, CD163: cluster of differentiation 163, FFA: free fatty acid, FBP: fructose-1,6-biphospatase, G6P: glucose-6-phosphate, G6Pase: glucose-6-phosphatase, GLUT4 = glucose transporter 4, GPx: glutathione peroxidase, GST: glutathione-S-transferase, GSH: glutathione, GR: glutathione reductase, HDL: high density lipoproteins, HMGB1: high mobility group box 1, HMGCoA reductase: 3-hydroxy-3-methyl-glutaryl-coenzyme A reductase, HOMAIR: homeostatic model of assessment-insulin resistance, IL-6: interleukin 6, IL-1ß: interleukin 1ß, LDL: low density lipoproteins, mRNA = messenger ribonucleic acid, NAFLD: nonalcoholic fatty liver disease, NADPH: nicotinamide adenine dinucleotide phosphate , NF- $\kappa$ B: nuclear factor kappa-light-chain-enhancer of activated B cells, SOD: superoxide dismutase, SREBP-1c: sterol regulatory element binding protein-1c, STZ: streptozotocin, SU: sulphonyl urea, TC: total cholesterol, TG: triglycerides, TGFb1: transforming growth factor beta 1.

\section{EFFECTS OF PLUMBAGIN ON DIABETES AND ITS MECHANISMS OF ACTION}

Plumbagin and plumbagin rich extracts have been reported to reduce plasma glucose level, increase insulin sensitivity, and improve glucose tolerance in different diabetic animal models. It could be that plumbagin exerts its antidiabetic effect through various mechanisms.

Insulin resistance is one of key predictors in the development of diabetes mellitus, therefore has become an important target of therapy ${ }^{27,28}$. Pai et al. (2019) reported that plumbagin administered in fructose induced diabetic rats improved glucose tolerance and reduced insulin resistance. Plumbagin treated groups $(0.5 \mathrm{mg} / \mathrm{kg}$ and $1 \mathrm{mg} / \mathrm{kg}$ body weight) reduced fasting plasma glucose level (5.66 and $5.12 \mathrm{mmol} / \mathrm{L})$, insulin (35.53 and $21.99 \mathrm{mIU} / \mathrm{L}$ ), and Homeostasis Model Assessment-Insulin Resistance (HOMA-IR) (8.96 and $5.54)$, when compared with diabetic rats $(7.64 \mathrm{mmol} / \mathrm{L}$, $62.02 \mathrm{mIU} / \mathrm{L}$, and 21.99, respectively). These findings suggest that plumbagin helps regulate glucose metabolism by improving insulin signaling, as also observed from the activation of glucose transporter type 4 (GLUT4) translocation in the skeletal muscles using animal model by other researchers ${ }^{29}$.

Glucose uptake into the cells is facilitated by GLUT4 transporters trafficked in the plasma membrane of muscle or fat cells ${ }^{30}$. The translocation of intracellular GLUT4 transporters into the membrane is regulated by insulin. Plumbagin at doses of 15 and $30 \mathrm{mg} / \mathrm{kg}$ body weight given orally for 28 days exerts antidiabetic 
effect in streptozotocin (STZ) induced diabetic rats, as observed in decreased level of plasma glucose compared to untreated group. Treatment with plumbagin (30 mg/kg body weight) in STZ induced diabetic rats elevated GLUT4 mRNA expression of the plasma membrane fractions of skeletal muscles, indicating increased level of GLUT4 compared to diabetic rats ${ }^{29}$. The observations suggest that plumbagin increases glucose uptake by restoring GLUT4 translocation to plasma membranes.

Plumbagin exerts its antidiabetic effect via modulation of enzymes involved in glycolysis and gluconeogenesis. Hexokinase is an enzyme involves in the initial step in glycolytic pathway. Phosphorylation of glucose by hexokinase leads to the formation of glucose-6-phosphate (G6P). Through several catalytic steps, G6P is broken down into pyruvates. Therefore, activation on hexokinase increase glucose utilization, thus help control plasma glucose level. Sunil et al. (2012) observed that treatment of diabetic induced rats for 28 days with plumbagin $(30 \mathrm{mg} / \mathrm{kg}$ body weight) increased hexokinase activity $(8.1 \mathrm{U} / \mathrm{mg}$ protein/min) compare to diabetic control and normal groups (4.99 and $8.73 \mathrm{U} / \mathrm{mg}$ protein $/ \mathrm{min})^{29}$.

Glycemic control may also be modulated by the inhibition of enzymes participating in gluconeogenesis, including glucose-6-phosphatase (G6Pase) and fructose1,6-biphospatase (FBP). Plumbagin inhibits hepatic gluconeogenesis by decreasing the activities of G6Pase and $\mathrm{FBP}^{29}$. Administration of plumbagin $(30 \mathrm{mg} / \mathrm{kg}$ body weight) in STZ induced diabetic rats for 28 days reduced the activities of G6Pase and FBP to 267 and 342 $\mathrm{U} / \mathrm{mg}$ protein/min respectively, compared to diabetic control group of both enzymes $(634 \mathrm{U} / \mathrm{mg}$ protein $/ \mathrm{min}$ ).

Zarmouh et al. (2012) studied the effect of root ethanolic extract of Plumbago zeylanica on diabetic rats induced by STZ. In this study tolbutamide-a sulphonyl urea (SU) drug-was used as a positive control. SU is known to stimulate the release of insulin by binding to $\beta$-cells SU receptors ${ }^{31}$. The extract was able to reduce plasma and urine glucose level. The antidiabetic of effect of $P$. zeylanica extract may be accounted to its ability to stimulate glucose utilization. Under diabetic condition, hepatic hexokinase activity is decreased, whereas glucose-6-phosphatase (G6Pase) activity is increased. $P$ zeylanica extract was observed to increase the activity of hexokinase, thus stimulating glycolysis. However, the extract decreased the activity of G6Pase, thus reducing gluconeogenesis. Rats treated with the extracts (100 and $200 \mathrm{mg} / \mathrm{kg}$ body weight) exerted analogous activities to tolbutamide $(250 \mathrm{mg} / \mathrm{kg}$ body weight $)$.

The antidiabetic effect of plumbagin can also be attributed to its inhibitory activity on $\alpha$-glucosidase. $\alpha$-Glucosidase in the ephythelium of the small intestine involves in the hydrolysis of polysaccharides into glucose.
Inhibition on $\alpha$-glucosidase delays the liberation of glucose from polysaccharides, thus delays its absorption into the blood circulation. Therefore, $\alpha$ glucosidase inhibition is an important strategy in modulating postprandial blood glucose level. Plumbagin has been shown to inhibit $\alpha$-glucosidase with an $\mathrm{IC}_{50}$ of $204 \pm 1.74 \mu \mathrm{g} / \mathrm{mL}$, compared to acarbose $\left(\mathrm{IC}_{50}\right.$ of $142.77 \pm 1.05 \mu \mathrm{g} / \mathrm{mL}$ ). This finding was supported by a docking study of the ligand plumbagin docked to $\alpha$-glucosidase ${ }^{32}$. In this study, plumbagin was shown to interact with two amino acids of $\alpha$-glucosidase (GLY228 and GLU-271), with binding energy affinity of -6.7 $\mathrm{kcal}$, which is acceptable in designing new drugs.

Under normal level of blood glucose, most of cellular glucose is phosphorylated into glucose-6-phosphate (G6P) by hexokinase. Only small amount of glucose enters polyol pathway. However, under hyperglycemic condition, around $30 \%$ of the body's glucose is channeled into the polyol pathway ${ }^{33}$. In this pathway, glucose is reduced into sorbitol (a poly alcohol form) by aldose reductase (AR) in the presence of NADPH. Sorbitol is later oxidized into fructose by sorbitol dehydrogenase. This pathway decreases the level of NADPH, which is required by glutathione reductase to regenerate reduced glutathione (GSH) from GSSG (oxidized form of glutathione). GSH is an endogenous antioxidant. Decreased level of GSH compromises the intracellular antioxidant capacity, resulting in increasing reactive oxygen species (ROS). Elevated level of ROS induces oxidative damage by oxidizing proteins, lipids, and DNA, which is key in the pathogenesis of diabetic complications. Plumbagin was reported to inhibit AR isolated from sheep kidney, with an $\mathrm{IC}_{50}$ of $1.05 \mu \mathrm{M}$. The Lineweaver-Burk plot revealed a non-competitive inhibition mechanism. By comparing the inhibition activity of plumbagin and other naphtoquinone derivatives, the study indicates that $\mathrm{OH}-$ moiety in $\mathrm{C} 5$ played a more important role in the inhibition than the methoxy group ${ }^{34}$.

Oxidation of free fatty acids (FFAs) is the primary stimulus of gluconeogenesis in the liver. In hyperglycemia condition, increase of FFA oxidation sends the signal to the liver to increase glucose production. Inhibition of fatty acid oxidation is a potential target in controlling hyperglycemia ${ }^{35}$. Cytochrome P450 enzymes are a family of enzymes involved in catalyzing $\omega$-hydroxylation of fatty acids ${ }^{36,37}$. Recently, Park et al. reported that P450 4A11 was highly upregulated in mouse liver of diet-induced diabetic mice, and suggested that inhibition of this enzyme improved glucose tolerance and ameliorated hepatic steatosis ${ }^{38}$. In studies using cytochrome P450 4A11 isolated from pooled human liver microsome, plumbagin was shown to inhibit $\omega$-hydroxylation of lauric acid in a concentration dependent manner $\left(\mathrm{IC}_{50} 1.7 \mu \mathrm{M}\right)$. The Lineweaver-Burk plot indicated a mixed inhibition mode ${ }^{39}$. 


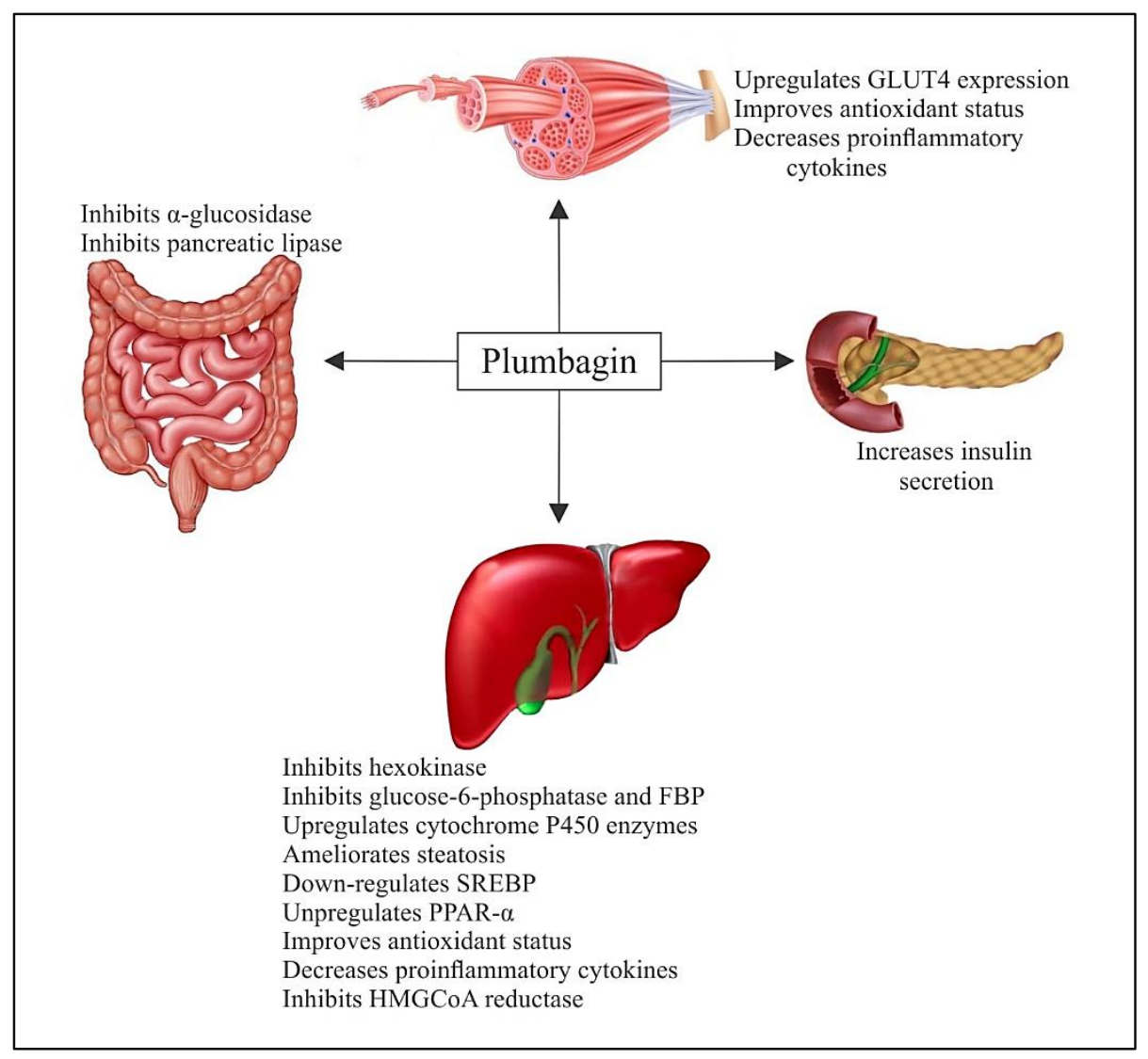

Figure 3. Possible mechanisms of action of plumbagin on the regulation of glucose and lipid metabolisms.

\section{EFFECTS OF PLUMBAGIN ON OBESITY AND LIPID PROFILES}

Obesity is a major risk factor in the development of metabolic syndromes, in particular diabetes mellitus and non-alcoholic fatty liver disease (NAFLD). Plumbagin and plant extracts rich in plumbagin have been proven to prevent obesity in several animal models, such as rats and rabbits induced by high fat diet $^{40,41}$ and rats induced by fructose $\operatorname{diet}^{42}$.

Obese rats treated orally with aqueous extract of Plumbago zeylanica roots $(20,40$, and $80 \mathrm{mg} / \mathrm{kg}$ body weight) for 15 days reduced serum total cholesterol and triglycerides concentrations significantly compared to untreated animals. The results were comparable to treated group with positive controls fenofibrate $(20 \mathrm{mg} / \mathrm{kg})$ and atorvastatin $(8 \mathrm{mg} / \mathrm{kg})$. In addition, treated groups exhibited a significant a decrease in hepatic lipid levels ${ }^{40}$. It is noting that HMGCoA reductase activity in the liver remained low, thus preventing cholesterogenesis.

Treatment with plumbagin $(30 \mathrm{mg} / \mathrm{kg}$ body weight) for 60 days in hyperlipidemic rabbits led to the reduction of serum cholesterol and LDL-cholesterol compared to negative control group. The treatment also prevented accumulation of hepatic cholesterol and triglycerides. Further, plumbagin administration prevented plaque formation in atheromatous rabbits ${ }^{41}$.

Plumbagin have been reported to improve serum lipid profiles in animal models. Shao et al. (2019) reported that treatment with plumbagin (10 and 20\%) in STZ-induced diabetic rats elevated HDL level and decreased serum levels of total cholesterol, triglyceride, and LDL compared to diabetic rats.

In term of the mechanisms of action of plumbagin as anti-obesity agent, plumbagin modulates different lipid and fatty acids metabolic pathways. The metabolism of fatty acids and lipids are regulated by lipogenesis and lipolysis. Various enzymes involved in lipogenesis, (i.e. fatty acid synthase and diglycerideacyltransferase) are regulated by sterol regulatory element binding proteins (SREBPs) ${ }^{43}$. In lipolysis, the process starts with the hydrolysis of triglycerides into FFAs. FFAs are then translocated into the cells by various transport proteins which are mostly regulated by peroxisome proliferator activated receptors (PPARs) ${ }^{44}$.

Pai et al. (2019) investigated anti-obesity effect of plumbagin on fructose induced obese rats. Administration of plumbagin at doses of 0.5 and $1 \mathrm{mg} / \mathrm{kg}$ body weight for 8 weeks reduced the body weight and serum fasting glucose in the rats. The study found that plumbagin administration decreased free fatty acid concentration in the liver and decreased the concentrations of inflammatory cytokines, including TNF- $\alpha$ and IL- 6 . Mitigation of obesity by plumbagin may be due to its modulation on SREBP-1c and PPAR- $\alpha$. When compared to disease control group, plumbagin also decreased 
mRNA expression of SREBP-1c, which is a regulator of enzymes involved in lipogenesis ${ }^{45}$. In addition, plumbagin increased mRNA expression of PPAR- $\alpha$, which is one of target genes for the regulation of enzymes participating in lipolysis ${ }^{44}$.

In contrast, plumbagin was shown to inhibit lipolysis. Study by Pai et al. (2018) showed that plumbagin inhibited porcine pancreatic lipase $\left(\mathrm{IC}_{50}\right.$ $82.08 \pm 9.47 \mu \mathrm{M}$ ), an enzyme that involves in the catalytic degradation of triglycerides. Inhibition kinetics study showed that plumbagin inhibited lipase in a mixed type mode. Docking study of the ligand-protein binding showed that plumbagin interacted with pancreatic lipase by noncovalent binding through Ser153 and the carbonyl moiety of the plumbagin. At cellular level, anti-obesity activity of plumbagin may also be accounted due to its ability to inhibit differentiation of adipocyte cells ${ }^{46}$.

\section{EFFECTS OF PLUMBAGIN ON DIABETIC COMPLICATIONS}

Diabetic chronic wounds are one of the most debilitating complications in diabetes. Prolonged hyperglycemia is known to inhibit cell proliferation and collagen production. Shao et al. (2019) reported that plumbagin (10 and 20\%) treated topically on diabetic rats significantly increased wound healing rate, reduced epithelization period, increased total collagen and total protein content. Plumbagin treatment increased the expression of transforming growth factor (TGF- $\beta$ ), which is important in the healing process. In addition, plumbagin treatment decreased inflammatory markers including TNF- $\alpha$, IL- 6 , and IL-1 $\beta$ levels. Further, plumbagin downregulated levels of CD68 and CD163 proteins ${ }^{47}$. CD68 and CD163 are glycoproteins which are highly expressed on macrophages in wounds ${ }^{48}$.

Diabetic nephropathy is one of serious complications in diabetics. Plumbagin was found to ameliorate diabetic nephropathy by modulating pathways involving NADPH oxidase 4 (Nox4). Nox4-a prooxidant enzyme was reported to be widely expressed in kidneys in the early stages of diabetic nephropathy. Oxidative stress which is induced in hyperglycemia condition contributes to the kidney hypertrophy, possibly through increased fibronectin expression and activation of myofibroblast induced by TGFb1. Administration of plumbagin on rat model of diabetic nephropathy proved to block Nox4 expression and down-regulate TGFb1 expression $^{49}$.

\section{PLUMBAGIN AS AN ANTIOXIDANT}

Persistent hyperglycemia has been noted to increase oxidative stress. In fact, oxidative stress has been implicated in the onset and complications in diabetes $^{50,51}$. In diabetic condition, multiple prooxidative pathways are upregulated that contribute to oxidative stress, including advanced glycation end-product (AGE), poly-ol, and protein kinase- $\mathrm{C}^{52}$. Shao et al. reported that lipid peroxidation level was increased in diabetic rats. The antioxidant enzymes (SOD, CAT, GPx, GR and GST) levels were also found to be lowered. However, administration of plumbagin (10 and 20\%) improved the antioxidant status of the treated groups, compared to untreated group $^{47}$, by increasing the activities of antioxidant enzymes and lowering reactive oxygen species (ROS). This finding correlates well with the reports of other researchers, who revealed plumbagin treatment on diabetic rats increased GSH, SOD, and catalase activities ${ }^{49,53}$.

\section{CONCLUSIONS}

To date, the literature confirms the antidiabetic and anti-obesity effects of plumbagin in pre-clinical setting. Plumbagin modulates multiple processes critical in the development of hyperglycemia and obesity. Plumbagin decrease insulin resistance, thus promotes glucose uptake. Plumbagin inhibits glycolysis and prevents gluconeogenesis by modulating key enzymes participating in the pathways. Plumbagin also prevents lipid accumulation in the liver by supressing lipogenesis. More mechanistic studies of plumbagin are needed to provide clear understanding on molecular targets and signalling pathways contributing to these effects. Further, there is no clinical study to support its use for the treatment of diabetes and obesity in the current practice. Clinical study is important in the development of plumbagin as a therapeutic agent for diabetes and obesity.

\section{ACKNOWLEDGEMENT}

$\mathrm{NB}$ is thankful for the support from Faculty of Medicine, Universitas Pembangunan Nasional Veteran Jakarta. AS acknowledges the support from the Faculty of Medicine and Health Sciences and Centre for Enzyme Research in Health and Diseases, both of Krida Wacana Christian University.

\section{Conflict of Interest}

Authors declare no conflicting interest.

\section{Funding}

The authors acknowledged the funding support from The Research Institute of Krida Wacana Christian University (Grant number: 20/UKKW/LPPM-FKIK/Lit/ XII/2019).

Ethics approval

None to declare. 


\section{Article info:}

Received May 1, 2021

Received in revised form July 8, 2021

Accepted July 12, 2021

\section{REFERENCES}

1. Chooi YC, Ding C, Magkos F. The epidemiology of obesity. Metabolism. 2019;92:6-10.

2. Chen L, Magliano DJ, Zimmet PZ. The worldwide epidemiology of type 2 diabetesmellitus-present and future perspectives. Nat Rev Endocrinol. 2012;8(4):228-36.

3. Esser N, Legrand-Poels S, Piette J, Scheen AJ, Paquot N. Inflammation as a link between obesity, metabolic syndrome and type 2 diabetes. Diabetes Res Clin Pract. 2014;105(2):141-50.

4. Tune JD, Goodwill AG, Sassoon DJ, Mather KJ. Cardiovascular consequences of metabolic syndrome. Transl Res. 2017; 183:57-70.

5. Glovaci D, Fan W, Wong ND. Epidemiology of diabetes mellitus and cardiovascular disease. Curr Cardiology Rep. 2019;21(4):1-8.

6. Saeedi P, Petersohn I, Salpea P, Malanda B, Karuranga S, Unwin $\mathrm{N}$, et al. Global and regional diabetes prevalence estimates for 2019 and projections for 2030 and 2045: Results from the International Diabetes Federation Diabetes Atlas, $9^{\text {th }}$ ed. Diabetes Res Clin Pract. 2019;157:107843.

7. World Health Organization. Global status report on noncommunicable diseases. 2014.

8. Williams R, Karuranga S, Malanda B, Saeedi P, Basit A, Besançon $\mathrm{S}$, et al. Global and regional estimates and projections of diabetes-related health expenditure: Results from the International Diabetes Federation Diabetes Atlas, $9^{\text {th }}$ ed. Diabetes Res Clin Pract. 2020;162:108072.

9. Tremmel M, Gerdtham U-G, Nilsson PM, Saha S. Economic burden of obesity: a systematic literature review. Int J Environ Res Public Health. 2017;14(4):435.

10. Simamora A, Timotius KH, Santoso AW. Antidiabetic, antibacterial and antioxidant activities of different extracts from Brucea javanica (L.) Merr seeds. Pharmacogn J. 2019;11(3): 479-85.

11. Timotius KH, Simamora A, Santoso AW. Chemical characteristics and in vitro antidiabetic and antioxidant activities of Premna serratifolia L. leaf infusion and decoction. Pharmacogn J. 2018;10(6):1114-8.

12. Li H, Yao Y, Li L. Coumarins as potential antidiabetic agents. J Pharm Pharmacol. 2017;69(10):1253-64.

13. Fomenko EV, Chi Y. Mangiferin modulation of metabolism and metabolic syndrome. BioFactors. 2016;42(5):492-503.

14. Meng S, Cao J, Feng Q, Peng J, Hu Y. Roles of chlorogenic acid on regulating glucose and lipids metabolism: a review. Evid Based Complement Alternat Med. 2013;2013.

15. Tripathi SK, Panda M, Biswal BKJF. Emerging role of plumbagin: cytotoxic potential and pharmaceutical relevance towards cancer therapy. Food Chem Toxicol. 2019;125:566-82.

16. Roy A. Plumbagin: A potential anti-cancer compound. Mini Rev Med Chem. 2020.

17. Onodera T, Kuriyama I, Sakamoto Y, Kawamura M, Kuramochi K, Tsubaki K, et al. 5-O-Acyl plumbagins inhibit DNA polymerase activity and suppress the inflammatory response. Arch Biochem Biophys 2015;573:100-10.

18. Zheng W, Tao Z, Chen C, Zhang C, Zhang H, Ying X, et al. Plumbagin prevents IL-1 $\beta$-induced inflammatory response in human osteoarthritis chondrocytes and prevents the progression of osteoarthritis in mice. Inflammation. 2017;40(3):849-60.

19. Tan M, Liu Y, Luo X, Chen Z, Liang H. Antioxidant activities of plumbagin and its $\mathrm{Cu}$ (II) complex. Bioinorg Chem Appl. 2011;2011.

20. Sundari BKR, Telapolu S, Bilikere S, Thyagarajan SP.
Cytotoxic and antioxidant effects in various tissue extracts of Plumbago zeylanica: Implications for anticancer potential. Pharm J. 2017;9(5):706-12.

21. Nair SV, Baranwal G, Chatterjee M, Sachu A, Vasudevan AK, Bose C, et al. Antimicrobial activity of plumbagin, a naturally occurring naphthoquinone from Plumbago rosea, against Staphylococcus aureus and Candida albicans. Int $\mathrm{J}$ Med Microbiol. 2016;306(4):237-48.

22. Dissanayake D, Perera D, Keerthirathna L, Heendeniya S, Anderson RJ, Williams DE, et al. Antimicrobial activity of Plumbago indica and ligand screening of plumbagin against methicillin-resistant Staphylococcus aureus. J Biomol Struct Dyn. 2020:1-12.

23. Petr B, Vojtech A, Ladislav H, Rene K. Noteworthy Secondary Metabolites Naphthoquinones-their Occurrence, Pharmacological Properties and Analysis. Curr Pharm Anal. 2009;5(1):47-68.

24. Van der Vijver LM. Distribution of plumbagin in the mplumbaginaceae. Phytochem. 1972;11(11):3247-8.

25. Hsieh Y-J, Lin L-C, Tsai T-H. Measurement and pharmacokinetic study of plumbagin in a conscious freely moving rat using liquid chromatography/tandem mass spectrometry. J Chromatogr B. 2006;844(1):1-5.

26. Rajalakshmi S, Vyawahare N, Pawar A, Mahaparale P, Chellampillai B. Current development in novel drug delivery systems of bioactive molecule plumbagin. Artif Cells Nanomed Biotechnol Rep. 2018;46(sup1):209-18.

27. Taylor R. Insulin resistance and type 2 diabetes. Diabetes. 2012;61(4):778-9.

28. Foretz M, Guigas B, Viollet BJNRE. Understanding the glucoregulatory mechanisms of metformin in type 2 diabetes mellitus. Nat Rev Endocrinol. 2019;15(10):569-89.

29. Sunil C, Duraipandiyan V, Agastian P, Ignacimuthu S. Antidiabetic effect of plumbagin isolated from Plumbago zeylanica L. root and its effect on GLUT4 translocation in streptozotocininduced diabetic rats. Food Chem Toxicol. 2012;50(12):4356-63.

30. Zaid H, Antonescu CN, Randhawa VK, Klip AJBJ. Insulin action on glucose transporters through molecular switches, tracks and tethers. Biochem J. 2008;413(2):201-15.

31. Levetan C. Oral antidiabetic agents in type 2 diabetes. Curr Med Res Opin. 2007;23(4):945-52.

32. Tuli HS, Bhatia GK, Sood S, Debnath P, Aggarwal D, Upadhyay SK. In silico analysis and molecular docking studies of plumbagin and piperine ligands as potential inhibitors of alpha-glucosidase receptor. Biointerface Res Appl Chem. 2021; 11(2):9629-37.

33. Fantus I. The pathogenesis of the chronic complications of the diabetes mellitus. Endocrinol Rounds. 2002;2(4):1-8.

34. Demir Y, Özaslan MS, Duran HE, Küfrevioğlu Öİ, Beydemir Ş. Inhibition effects of quinones on aldose reductase: Antidiabetic properties. Environ Toxicol Pharmacol. 2019;70:103195.

35. Foley JE. Rationale and application of fatty acid oxidation inhibitors in treatment of diabetes mellitus. Diabetes Care. 1992; 15(6):773-84.

36. Johnston JB, Ouellet H, Podust LM, de Montellano PRO. Structural control of cytochrome P450-catalyzed $\omega$-hydroxylation. Arch Biochem Biophys. 2011;507(1):86-94.

37. Johnson AL, Edson KZ, Totah RA, Rettie AE. Cytochrome P450 $\omega$-hydroxylases in inflammation and cancer. Adv Pharmacol. 2015;74:223-62

38. Park EC, Kim SI, Hong Y, Hwang JW, Cho G-S, Cha H-N, et al. Inhibition of CYP4A reduces hepatic endoplasmic reticulum stress and features of diabetes in mice. Gastroenterology. 2014; 147(4):860-9.

39. Choi YJ, Zhou Y, Lee J-Y, Ryu CS, Kim YH, Lee K, et al. Cytochrome P450 4A11 inhibition assays based on characterization of lauric acid metabolites. Food Chem Toxicol. 2018;112: 205-15.

40. Pendurkar SR, Mengi SA. Antihyperlipidemic effect of aqueous extract of Plumbago zeylanica roots in diet-induced hyperli- 
pidemic rat. Pharm Biol. 2009;47(10):1004-10.

41. Sharma I, Gusain D, Dixit VJIJPP. Hypolipidaemic and antiatherosclerotic effects of plumbagin in rabbits. Indian J Physiol Pharmacol. 1991;35(1):10-4.

42. Pai SA, Munshi RP, Panchal FH, Gaur IS, Mestry SN, Gursahani MS, et al. Plumbagin reduces obesity and nonalcoholic fatty liver disease induced by fructose in rats through regulation of lipid metabolism, inflammation and oxidative stress. Biomed Pharmacother. 2019;111:686-94.

43. Horton JD. Sterol regulatory element-binding proteins: transcriptional activators of lipid synthesis. Biochem Soc Trans. 2002;30(6):1091-5.

44. Rakhshandehroo M, Knoch B, Müller M, Kersten S. Peroxisome proliferator-activated receptor alpha target genes. PPAR Res. 2010;2010.

45. Ferre P, Foufelle F. Hepatic steatosis: a role for de novo lipogenesis and the transcription factor SREBP-1c. Diabetes Obes Metab. 2010;12:83-92.

46. Pai SA, Martis EAF, Joshi SG, Munshi RP, Juvekar AR. Plumbagin exerts antiobesity effects through inhibition of pancreatic lipase and adipocyte differentiation. Phytother Res. 2018;32(8):1631-5.

47. Shao Y, Dang M, Lin Y, Xue F. Evaluation of wound healing activity of plumbagin in diabetic rats. Life Scie. 2019;231:
116422.

48. Schaer DJ, Schaer CA, Buehler PW, Boykins RA, Schoedon G, Alayash AI, et al. CD163 is the macrophage scavenger receptor for native and chemically modified hemoglobins in the absence of haptoglobin. Blood. 2006;107(1):373-80.

49. Yong R, Chen XM, Shen S, Vijayaraj S, Ma Q, Pollock CA, et al. Plumbagin ameliorates diabetic nephropathy via interruption of pathways that include NOX4 signalling. PLoS ONE. 2013;8(8).

50. Cecilia O-M, José Alberto C-G, José N-P, Ernesto Germán CM, Ana Karen L-C, Luis Miguel R-P, et al. Oxidative stress as the main target in diabetic retinopathy pathophysiology. J Diabetes Res. 2019;2019.

51. Ceriello A, Testa R, Genovese S. Clinical implications of oxidative stress and potential role of natural antioxidants in diabetic vascular complications. Nutr Metab Cardiovasc Dis. 2016;26(4):285-92.

52. Ighodaro OMJB. Molecular pathways associated with oxidative stress in diabetes mellitus. Biomed Pharmacother. 2018;108: 656-62.

53. Pai SA, Munshi RP, Panchal FH, Gaur I-S, Mestry SN, Gursahani MS, et al. Plumbagin reduces obesity and nonalcoholic fatty liver disease induced by fructose in rats through regulation of lipid metabolism, inflammation and oxidative stress. Biomedicine \& Pharmacotherapy. 2019;111:686-94. 